\title{
Miscarriage, Perceived Ostracism, and Trauma: A Preliminary Investigation
}

\section{Eric D. Wesselmann ${ }^{1 *}$ and Leandra Parris ${ }^{2}$ \\ ${ }^{1}$ Department of Psychology, Illinois State University, Normal, IL, United States, ${ }^{2}$ College of William \& Mary, Williamsburg, VA, United States}

Miscarriage often is a traumatic experience with serious mental health implications. Friends and family members are often uncomfortable with and avoid discussing the topic with bereaved individuals, potentially making them feel ostracized (i.e., being ignored and excluded), contributing to their mental health concerns. We investigated the correlation between posttraumatic stress symptoms, perceived ostracism, and recalled grief intensity measures in a sample of cisgender women $(N=97)$ who have had

OPEN ACCESS

Edited by:

Lonneke I. M. Lenferink,

University of Twente, Netherlands

Reviewed by:

Carina Heeke,

Freie Universität Berlin, Germany Dorte Hvidtjørn,

University of Southern Denmark,

Denmark

${ }^{*}$ Correspondence:

Eric D. Wesselmann

edwesse@ilstu.edu

Specialty section:

This article was submitted to Personality and Social Psychology,

a section of the journal

Frontiers in Psychology

Received: 26 July 2021

Accepted: 23 December 2021

Published: 27 January 2022

Citation:

Wesselmann ED and Parris L

(2022) Miscarriage, Perceived

Ostracism, and Trauma: A Preliminary

Investigation.

Front. Psychol. 12:747860.

doi: 10.3389/fpsyg.2021.747860 a miscarriage. These participants were recruited using Qualtrics's Panel Recruitment Services. Women's perceived ostracism correlated positively with posttraumatic stress symptoms and negatively with grief congruence (i.e., the degree to which they felt that their miscarriage process was as satisfactory as possible, given they had to experience it). Perceived ostracism also explained additional variance in posttraumatic stress symptoms when considered alongside grief intensity measures (e.g., congruence).

Keywords: miscarriage, trauma, posttraumatic stress, ostracism, perinatal loss and grief

\section{INTRODUCTION}

Miscarriage often is a painful, traumatic experience for women (Kersting and Wagner, 2012). In addition to experiencing grief expressions (e.g., sadness, denial) similar to other forms of bereavement (Lasker and Toedter, 1991; Brier, 2008), women who experience miscarriage may also exhibit posttraumatic stress symptoms such as avoiding reminders and involuntarily reliving the event (Farren et al., 2016; Christiansen, 2017). Miscarriage also can lead to other mental health concerns such as anxiety-related and major depressive disorders (Swanson et al., 2009; Gold et al., 2014; Murphy et al., 2014).

There are several ways of conceptualizing and measuring the grief caused by miscarriage and other forms of perinatal loss (e.g., stillbirth), each approach having its own focus on grief manifestations (e.g., behavioral, affective, cognitive), strengths, and limitations (Setubal et al., 2021). One approach, the Perinatal Grief Intensity Theoretical Framework/Scale (Hutti and Baker, 2020), focuses on women's perceptions of their miscarriage experience. Specifically, the framework identifies three factors that influence the intensity of the grief experience and associated mental health concerns for women post-miscarriage. Data demonstrate the experience often is more intense for women who felt the pregnancy was more "real" to them (reality factor), who did 
not feel they could confront others that said hurtful or dismissive things about the miscarriage (confrontation factor), and/or did not feel the overall process of the miscarriage was handled as well as could be expected (congruence factor; Hutti et al., 1998, 2013, 2014, 2018). Scores on these factors predict posttraumatic stress symptoms (Hutti et al., 2014), as well as mental health outcomes that co-occur with posttraumatic stress, such as anxiety and depression symptoms (Hutti and Baker, 2020). Given the mental health implications, it is imperative that researchers and clinicians understand the diverse social factors that influence women's miscarriage experiences, grief, and trauma symptoms.

\section{Ostracism: A Contributing Factor to Miscarriage-Related Traumatic Stress?}

In addition to typical concerns with negotiating grief, miscarriage may also involve feeling socially isolated from friends, family, and co-workers (Herz, 1984; Panuthos and Romeo, 1984). For example, qualitative data suggest that individuals who have experienced miscarriage or other forms of perinatal loss can sometimes feel like others do not acknowledge their loss (McCreight, 2004), and other research has found that these individuals can report feelings of loneliness, isolation, and being devalued (i.e., Potvin et al., 1989). One possibility is that people may feel uncomfortable talking to the bereaved individual about the loss and thus become less emotionally available or avoid the topic altogether (Harmon et al., 1984; Stroebe et al., 2013). Some individuals may minimize the bereaved person's grief or not recognize their loss at all (Renner et al., 2000). In extreme circumstances, individuals may withdraw from the bereaved individuals entirely, as reported by bereaved individuals in other contexts (e.g., Breen and O'Connor, 2011).

Bereaved individuals who experience this lack of social support likely feel ostracized - a form of social exclusion characterized by feeling ignored or invisible in relationships (Williams, 2009). Ostracized individuals experience various negative psychological outcomes, such as emotional pain, feelings of being devalued, and threats to basic psychological needs (e.g., belonging, self-esteem). These outcomes occur even when the ostracism is innocuous, brief, or ambiguous, such as when someone does not receive expected text messages, social media feedback, or eye contact (Williams, 2009; Wolf et al., 2015). Additionally, various studies demonstrate that the negative effects evoked by ostracism can be re-experienced when individuals reflect on the event, even if several years have passed since the initial event (e.g., Chen et al., 2008).

Germane to the current topic, research also suggests that feeling ostracized can prolong distress (e.g., posttraumatic stress symptoms) in individuals who have experienced various forms of trauma. For example, one study (Wesselmann et al., 2018) demonstrated that perceived ostracism predicted posttraumatic stress symptoms in a sample of military veterans beyond selfreported combat stressors and perceived social support. Another study (Nietlisbach and Maercker, 2009) demonstrated that selfidentified trauma survivors (e.g., accidents, natural disasters, and sexual assault) experienced significantly more short-term stress symptoms after being ostracized than control participants.
Though only marginally significant, ostracized survivors reported experiencing more anxiety and psychoticism symptoms than included survivors. Time since the initial trauma did not seem to matter as the average was 9.4 years, ranging from 1 to 27 years. Given these two studies, perceived ostracism likely would have a similar effect on individuals who have experienced other forms of trauma, such as miscarriage.

\section{Current Research}

To our knowledge, there has yet to be a systematic study of the degree to which individuals who have experienced miscarriage feel ostracized. However, extant literature supports a potential connection. Some research has found gender differences in the grieving process (Kersting and Wagner, 2012); as such, we focus our current study on cisgender women to avoid gender and sex as potential confounds. First, we hypothesized that women's recalled grief intensity will correlate with posttraumatic stress symptoms, replicating past research (e.g., Hutti et al., 1998). Specifically, the reality factor will exhibit a positive correlation, and the confrontation and congruence factors will have negative correlations (Hypothesis 1).

Next, we examined our theorized links between perceived grief intensity, posttraumatic stress symptoms, and ostracism. We expected that women's perceived ostracism will correlate positively with recalled grief intensity. Specifically, the confrontation and congruence factors will have negative correlations; these two factors explicitly deal with interpersonal interactions within the context of a miscarriage experience (Hypothesis 2a). We had no hypothesis for the reality factor because this factor does not pertain to interpersonal interactions. We also hypothesized that women's perceived ostracism will correlate positively with posttraumatic stress symptoms (Hypothesis 2b). Such a correlation would replicate past research investigating ostracism with other forms of trauma (e.g., Wesselmann et al., 2018). Finally, because this study is a preliminary investigation, we chose to explore if perceived ostracism predicts incremental variance beyond grief intensity factors (Research question 1a) and the relative importance of each individual predictor (Research question $1 \mathrm{~b}$ ).

\section{METHOD}

\section{Participants}

This study was approved by the IRB at Illinois State University. We recruited participants using Qualtrics's Panel Recruitment Services, which offers researchers the opportunity to recruit a sample of participants from their survey respondent pool that meets specified selection criteria. We specifically requested cisgender women, 18 years of age or older, who report living in the U.S. and had experienced at least one miscarriage. Further, we provided two attention checks throughout the survey (e.g., "This is an attention check: Please select " 2 " for this question."). Qualtrics removed any participant who did not pass these two checks from the final dataset. After conducting a pilot study ( $\sim 20$ participants), Qualtrics determined the median completion time was $8 \mathrm{~min}$, so they created a speeding check to filter out 
participants who completed the study in under $4 \mathrm{~min}$. This is standard practice for Qualtrics panels. Upon completion, participants received debriefing information and links to online mental health resources. Qualtrics then compensated participants with redeemable vouchers for various products, per their standard panel service recruiting procedures.

Ninety-seven women from 18 to 87 years of age $(M=51.00$, $S D=18.34)$ with an average of 1.54 miscarriages (Mode $=1$, $S D=0.85$, Min $=1$, Max $=5$ ) participated. Most participants identified as White/Caucasian (79.8\%), with 3.4\% as AsianAmerican/Asian Descent, 8.4\% Black/African American, 8.4\% Hispanic/Latina, 2.5\% Native American/American Indian, 2.5\% Bi-/Multi-Racial, and $3.4 \%$ unspecified. Most participants $(52.6 \%)$ were in long-term relationships (married/legal partnerships), with $23.7 \%$ divorced/separated, $15.5 \%$ single, and $8.2 \%$ widowed.

\section{Procedure and Measures}

After providing consent to participate, participants were given a quality check commonly used in Qualtrics Panel studies. This question asked participants if they "commit to providing your thoughtful and honest answers in this survey?" Participants can choose: Yes, No, or I can't commit either way. Only participants who chose "Yes" could continue. Then, participants completed basic demographics, which included the gender and miscarriage screener items. Additionally, we asked how many miscarriages they have had and how long ago (in months) was their most recent miscarriage. Participants meeting our criteria continued on with our measures; participants who did not indicate they had had at least one miscarriage were redirected to a different study.

\section{Recalled Grief Intensity}

We used the Perinatal Grief Intensity scale (Hutti et al., 1998) to measure participants recalled grief experiences. The measure has 14 items assessing three separate factors: reality (6 items, e.g., "I felt I had lost my son or my daughter, not just my pregnancy.", Cronbach's $\alpha=0.87$ ), confront (4 items, e.g., "In the first hours and days after my miscarriage, if people said or did things that made me feel bad, I was able to ask them to stop.", Cronbach's $\alpha=0.88$ ), and congruence (4 items, e.g., "During and after my miscarriage, I was satisfied with the way my miscarriage experience unfolded, given I had to go through it.", Cronbach's $\alpha=0.85)$. Participants answered based upon their most recent miscarriage, using a 7-point scale (1-Strongly Disagree, 7Strongly Agree). We averaged the items for each factor, such that higher scores indicated higher average endorsement.

\section{Perceived Ostracism}

Participants indicated how much they perceived being ostracized in their daily lives because of their most recent miscarriage, on a 10-item measure using a 7-point scale (1-Hardly Ever; 7-Almost Always; e.g., "Because of my miscarriage, I feel ignored" and "Because of my miscarriage, others treat me as if I'm in solitary confinement"; Cronbach's $\alpha=0.97$ ). This measure has been used in a general format to examine the negative impact of perceived ostracism in adolescent (Gilman et al., 2013) and military samples
(Wesselmann et al., 2018). We scored and averaged the items such that higher scores indicated higher perceived ostracism.

\section{Posttraumatic Stress Symptoms}

We used the PTSD Checklist for DSM-5 (PCL-5; Weathers et al., 2013) to assess participants' self-reported posttraumatic stress symptoms. Participants answered 20 items based on the DSM-5 diagnostic criteria, rating the degree to which they had experienced each symptom within the past month (1-Not At All, 5-Extremely; Cronbach's $\alpha=0.97$ ). We instructed participants to answer each question regarding their most recent miscarriage, adding reference to the miscarriage whenever possible in the items (e.g., "In the past month, how often were you bothered by repeated, disturbing dreams of the miscarriage."). We scored and averaged the items such that higher scores indicated higher reported posttraumatic stress symptoms. ${ }^{1}$

\section{Statistical Analyses}

There were no missing data in our predictor or outcome measures. Participants had a wide range of time (in months) since their most recent miscarriage $(2-816$ mo.; $M=243, S D=212.44$; converted to years as $M=20.25, S D=17.70)$. Because grief effects can decrease over time (Cuisinier et al., 1993), we used this as a control variable in all analyses. We examined Hypotheses 1 and 2 using bivariate partial correlations. We examined Research Question 1a using multiple regression analyses. A complimentary approach involves examining the relative importance of each predictor compared to the others in the model (Tonidandel and LeBreton, 2011; 2015). Thus, we examined Research Question 1b using a relative weights analysis (Johnson, 2000) to determine the relative contributions of the three grief intensity factors and perceived ostracism on posttraumatic stress symptoms. This analysis examined each predictor's relative importance accounting for both the predictor's direct effect and its effect when combined with the other predictors in the model (Johnson and LeBreton, 2004). The analysis was implemented using RWA-Web (Tonidandel and LeBreton, 2015). We calculated rescaled relative weights by dividing each relative weight by the $\mathrm{R}$ of the model.

\section{RESULTS}

Hypothesis 1 focused on replicating correlations found in previous research (Table 1). As expected, we found that two of the three recalled grief intensity factors correlated significantly with symptoms: the more that participants recalled being able to confront people about problematic interactions, and the more they recalled their miscarriage experience corresponding with their desire of care, the fewer trauma symptoms they reported $(r s=-0.26$ and $-0.54, p s \leq 0.010)$. We found a marginally significant positive correlation between reality and trauma symptoms $(r=0.19, p=0.066)$.

\footnotetext{
${ }^{1}$ We collected a measure of basic need satisfaction and psychological distress as additional outcome measures. As in other research, higher perceived ostracism correlated with lower basic need satisfaction. The results for psychological distress
} 
TABLE 1 | Descriptive statistics, inter-correlation matrix, and scale reliabilities.

\begin{tabular}{|c|c|c|c|c|c|c|c|c|c|}
\hline & $M$ & $S D$ & Range & 1 & 2 & 3 & 4 & 5 & 6 \\
\hline $\begin{array}{l}\text { 1. \# of } \\
\text { Miscarriages }\end{array}$ & 1.54 & 0.85 & 4 & & & & & & \\
\hline 2. Grief: Reality & 5.14 & 1.61 & 6 & 0.12 & $(0.87)$ & & & & \\
\hline $\begin{array}{l}\text { 3. Grief: } \\
\text { Confrontation }\end{array}$ & 4.36 & 1.68 & 6 & -0.05 & -0.05 & $(0.88)$ & & & \\
\hline $\begin{array}{l}\text { 4. Grief: } \\
\text { Congruence }\end{array}$ & 4.40 & 1.56 & 6 & -0.09 & -0.16 & $0.56^{* *}$ & $*(0.85)$ & & \\
\hline $\begin{array}{l}\text { 5. Posttraumatic } \\
\text { stress symptoms }\end{array}$ & 2.54 & 1.15 & 4 & 0.08 & $0.19^{\dagger}$ & $-0.26^{*}$ & $-0.54^{* *}$ & $(0.97)$ & \\
\hline $\begin{array}{l}\text { 6. Perceived } \\
\text { ostracism }\end{array}$ & 2.07 & 1.46 & 6 & $0.20^{\dagger}$ & -0.09 & -0.04 & $-0.34^{* *}$ & $0.54^{* *}$ & $(0.97)$ \\
\hline
\end{tabular}

Hypothesis 2a focused on the correlations between women's perceived ostracism and the three factors of their recalled grief intensity. Perceived ostracism only correlated significantly with grief congruence, such that the more participants recalled their grief experience as being congruent with their expectations, the less they felt ostracized $(r=-0.34, p=0.001)$. Hypothesis $2 \mathrm{~b}$ focused on the correlation between women's perceived ostracism and their posttraumatic stress symptoms, for which we found a significant positive correlation $(r=0.54, p<0.001)$.

For Research Question 1a, we explored if perceived ostracism predicts incremental variance beyond grief intensity factors. Perceived ostracism explained additional variance in posttraumatic stress symptoms beyond the three grief intensity factors: $\Delta R^{2}=0.12, F(1,91)=26.99, p<0.001$. The full results are presented in Table 2. For Research Question 1b we examined the relative importance of each predictor compared to the others in the model and found that perceived ostracism (40.99\%; raw weight $=0.24$ ) explained the most variance, followed by the grief congruence factor $(26.10 \%$; raw weight $=0.15)$, length of time since the most recent miscarriage $(23.77 \%$; raw weight $=0.14)$, grief confront $(5.86 \%$; raw weight $=0.03)$, and grief reality $(2.27 \%$, raw weight $=0.02)$.

\section{DISCUSSION}

We provide preliminary empirical evidence for a connection between perceived ostracism and women's miscarriagerelated posttraumatic stress symptoms. Specifically, women who perceived more ostracism reported higher levels of posttraumatic stress symptoms, with a large effect size (Murphy and Myors, 2004). Further, it explained additional variance when considered alongside established grief intensity factors, this time with a medium effect size. Indeed, it predicted the most amount of variance comparatively. Thus, our data suggest that researchers interested in miscarriage-related grief and posttraumatic stress should consider how perceived ostracism may contribute to-and prolong-these processes. Such connections would have important implications for mental

were similar to those for posttraumatic stress symptoms, albeit with smaller effect sizes. Data available upon request.
TABLE 2 | Incremental variance explained by perceived ostracism over grief components.

\begin{tabular}{|c|c|c|c|c|}
\hline \multicolumn{5}{|c|}{ Outcome: Posttraumatic stress symptoms } \\
\hline Step & Model summary & Predictor variable & B & $\Delta R^{2}$ \\
\hline 1 & $\begin{array}{c}R^{2}=0.23, F \\
(1,95)=28.74^{\star \star \star}\end{array}$ & $\begin{array}{c}\text { Time since Last } \\
\text { Miscarriage }\end{array}$ & $-0.48^{* * *}$ & \\
\hline \multirow[t]{4}{*}{2} & $\begin{array}{c}R^{2}=0.47, F \\
(4,92)=20.11^{\star \star \star}\end{array}$ & $\begin{array}{l}\text { Time since Last } \\
\text { Miscarriage }\end{array}$ & $-0.41^{* * *}$ & \\
\hline & & Reality & 0.09 & \\
\hline & & Confrontation & 0.05 & \\
\hline & & Congruence & $-0.49^{* * *}$ & $0.23^{* * *}$ \\
\hline \multirow[t]{5}{*}{3} & $\begin{array}{c}R^{2}=0.59, F \\
(5,91)=26.03^{\star \star \star}\end{array}$ & $\begin{array}{l}\text { Time since Last } \\
\text { Miscarriage }\end{array}$ & $-0.28^{* * *}$ & \\
\hline & & Reality & $0.15^{*}$ & \\
\hline & & Confrontation & -0.04 & \\
\hline & & Congruence & $-0.30^{* *}$ & \\
\hline & & Perceived Ostracism & $0.41^{* * *}$ & $0.12^{* * *}$ \\
\hline
\end{tabular}

${ }^{*} p<0.050,{ }^{* *} p=0.001,{ }^{* * *} p<0.001$. Betas are standardized.

health treatment plans used with women whose presenting concerns involve miscarriage.

These data provide an important first step but there are several factors limiting the generalizability of our results. We used a cross-sectional survey approach and are thus limited in any causal interpretations of our data. Additionally, we did not specify that participants had to be within a set timeframe postmiscarriage; for some participants it may have been a matter of a few months, and for others it may have been several years. However, we do not believe this limitation presents an alternative explanation for our results. Previous research has established that the emotional pain of ostracism can be reexperienced long after the initial event occurred (e.g., Chen et al., 2008). Even though grief reactions tend to dissipate over time (Cuisinier et al., 1993) some research has found that negative effects can linger for several years (Murphy et al., 2014). Indeed, some qualitative studies found that people report experiencing the pain of losing a child (either through miscarriage or to a terminal illness post-birth) for several decades (McClowry et al., 1987; Hazen, 2003). Some bereavement experts have argued that for many people the pain may never go away completely (e.g., Corr, 1998-99). Trauma experts have argued that there is no specific timeframe for when trauma can no longer manifest and it can become a chronic condition that impacts individuals over the lifespan (Van Der Kolk, 2015; National Institute of Mental Health, 2019). This may be especially true for individuals who were not allowed to mourn their loss (Hazen, 2003). Finally, any dissipation occurring in our sample would have made it more difficult for us to find any relations between our measures, yet we still did. In our study, length of time was only the third largest predictor of variance in a relative weights analysis, whereas perceived ostracism and grief congruence were the first and second largest, respectively. Regardless, future research should replicate these findings using multi-wave longitudinal survey designs with larger samples to examine the temporal structure of grief intensity, perceived ostracism, and posttraumatic stress symptoms. 
There are other demographic factors which we did not assess that may also influence our variables of interest, such as education, socioeconomic status, number of living children, gestational age when the miscarriage occurred, or reason for the miscarriage. People may be less willing to support a bereaved mother if the miscarriage occurred early in gestation or if she has other living children. Future research should investigate the degree to which these factors influence the connection between perceived ostracism and trauma symptoms. Additionally, we did not specifically screen participants for clinical diagnoses of posttraumatic stress disorder. Rather we simply included all participants' data using the continuous nature of our outcome measure, regardless of whether it reached a clinical threshold. It is important to note that two previous studies investigating the connection between ostracism and trauma symptoms did not restrict their sampling to a clinical population either and still found consistent effects that converge with our current findings (Nietlisbach and Maercker, 2009; Wesselmann et al., 2018). Regardless, these effects may be intensified in a clinical population.

Similarly, we used the Perinatal Grief Intensity scale as a continuous variable rather than a clinical screening tool. As with the posttraumatic stress measure, it is likely that the effect sizes would be magnified for individuals who fit the criteria for a clinical diagnosis of intense grief responses. As previously mentioned, there are multiple grief measures used in research on perinatal loss, each with their individual foci, strengths, and limitations (Setubal et al., 2021). Future research should investigate how these measures relate to perceived ostracism, posttraumatic stress, and other grief-related phenomena. For example, the Perinatal Grief Scale is another common measure (Toedter et al., 1988). Data suggest that the measure we used is comparable with this scale (Hutti et al., 2017; Hutti and Baker, 2020), yet it would be useful to examine these relations directly as a conceptual replication. Future research should also investigate how perceived ostracism relates to the experience of prolonged grief - an attachment related disorder that involves threats to one's sense of meaning, identity, and a yearning for the deceased person. Prolonged grief often co-occurs with other mental health concerns such as posttraumatic stress, depression, and anxiety, yet it is a distinct construct that researchers interested in both perinatal loss and perceived ostracism should consider (Prigerson et al., 2021).

Finally, our sample also is limited to cisgender women. We cannot generalize our findings to transgender women, or to cis- and transgender men, or individuals with non-binary gender identities. Previous research suggests that although men also experience grief, posttraumatic stress symptoms, and other mental health issues post-miscarriage, the processes and intensity can differ from those of women (Johnson and Baker, 2004; McCreight, 2004; Kersting and Wagner, 2012). In some cases, cultural expectations such as viewing men's role solely as being a support partner may lead friends, family, and even medical staff to ignore their grief (Jones et al., 2019). Gender identity may complicate this process further. Individuals who hold transgender or non-binary gender identities often experience discrimination via purposeful misgendering, which can make them feel excluded/ignored (Wesselmann et al., 2021). If these individuals have friends, family, or medical personal who refuse to use their preferred parental terms or refuse to acknowledge their parental status, they are likely to experience additional ostracism that cisgender individuals do not.

Additionally, connecting the ostracism and miscarriage literature provides an opportunity to examine the complex nature of disenfranchised grief, a type of grief "persons experience when they incur a loss that is not or cannot be openly acknowledged, publicly mourned, or socially supported" (Doka, 1989, p.4). Research on disenfranchised grief suggests it is a multifaceted experience involving both interpersonal and structural factors, all of which combine to make the bereaved person feel that some aspect of their grief is invalidated, devalued or unrecognized (Corr, 1998-99). Qualitative research demonstrates that women who have had miscarriages indicate both interpersonal and system-level experiences relevant to disenfranchised grief in other bereavement contexts (Hazen, 2003; Lang et al., 2011; Mulvihill and Walsh, 2014). Based on our data, perceived ostracism seems to be an important interpersonal factor that contributes to this overall experience and should be considered by researchers interested in this construct, both within the context of miscarriage and bereavement broadly.

\section{DATA AVAILABILITY STATEMENT}

The original contributions presented in the study are publicly available. This data can be found here: https://osf.io/vkz23/.

\section{ETHICS STATEMENT}

The studies involving human participants were reviewed and approved by Illinois State University Institutional Review Board. Written informed consent for participation was not required for this study in accordance with the national legislation and the institutional requirements.

\section{AUTHOR CONTRIBUTIONS}

Both authors listed have made a substantial, direct, and intellectual contribution to the work, and approved it for publication.

\section{FUNDING}

This research was funded by the Summer Faculty Fellowship, Faculty Research Award, and Faculty Publication Support grants from Illinois State University's College of Arts and Sciences, Office of Research and Graduate Studies, Department of Psychology, and the College of William and Mary's School of Education.

\section{ACKNOWLEDGMENTS}

The authors dedicate this paper to the children we have lost: Timothy, Ember, and Tristan Wesselmann, and Hope Griffis. We also thank the participants who completed our surveys. 


\section{REFERENCES}

Breen, L. J., and O'Connor, M. (2011). Family and social networks after bereavement: experiences of support, change and isolation. J. Fam. Ther. 33, 98-120. doi: 10.1111/j.1467-6427.2010.00495.x

Brier, N. (2008). Grief following miscarriage: a comprehensive review of the literature. J. Women Health 17, 451-464. doi: 10.1089/jwh.2007.0505

Chen, Z., Williams, K. D., Fitness, J., and Newton, N. C. (2008). When hurt will not heal: exploring the capacity to relive social and physical pain. Psychol. Sci. 19, 789-795. doi: 10.1111/j.1467-9280.2008.02158.x

Christiansen, D. M. (2017). Posttraumatic stress disorder in parents following infant death: a systematic review. Clin. Psychol. Rev. 51, 60-74. doi: 10.1016/ j.cpr.2016.10.007

Corr, C. A. (1998-99). Enhancing the concept of disenfranchised grief. OMEGA J. Death Dying 38, 1-20. doi: 10.2190/LD26-42A6-1EAV-3MDN

Cuisinier, M. C. J., Kuijpers, J. C., Hoogduin, C. A. L., De Graauw, C. P. H. M., and Janssen, H. J. E. M. (1993). Miscarriage and stillbirth: time since the loss, grief intensity and satisfaction with care. Eur. J. Obstetr. Gynecol. Reprod. Biol. 52, 163-168. doi: 10.1016/0028-2243(93)90066-L

Doka, K. J. (1989). "Disenfranchised grief," in Disenfranchised Grief: Recognizing Hidden Sorrow, ed. K. J. Doka (Lexington, MA: Lexington Books), 3-11.

Farren, J., Jalmbrant, M., Ameye, L., Joash, K., Mitchell-Jones, N., Tapp, S., et al. (2016). Post-traumatic stress, anxiety and depression following miscarriage or ectopic pregnancy: a prospective cohort study. BMJ Open 6:e011864. doi: 10.1136/bmjopen-2016-011864

Gilman, R., Carter-Sowell, A., DeWall, C. N., Adams, R. E., and Carboni, I. (2013). Validation of the ostracism experience scale for adolescents. Psychol. Assess. 25, 319-330. doi: 10.1037/a0030913

Gold, K. J., Boggs, M. E., Muzik, M., and Sen, A. (2014). Anxiety disorders and obsessive compulsive disorder 9 months after perinatal loss. Gen. Hosp. Psychiatry 36, 650-654. doi: 10.1016/j.genhosppsych.2014.09.008

Harmon, R. J., Glicken, A. D., and Siegel, R. E. (1984). Neonatal loss in the intensive care nursery: effects of maternal grieving and a program for intervention. J. Am. Acad. Child Psychiatry 23, 68-71. doi: 10.1097/00004583-198401000-00009

Hazen, M. A. (2003). Societal and workplace responses to perinatal loss: disenfranchised grief or healing connection. Hum. Relat. 56, 147-166. doi: $10.1177 / 0018726703056002889$

Herz, E. (1984). Psychological repercussions of pregnancy loss. Psychiatr. Ann. 14, 454-457. doi: 10.3928/0048-5713-19840601-11

Hutti, M. H., Armstrong, D. S., and Myers, J. (2013). Evaluation of the perinatal grief intensity scale in the subsequent pregnancy after perinatal loss. J. Obstet. Gynecol. Neonatal. Nurs. 42, 697-706.

Hutti, M. H., Armstrong, D. S., and Myers, J. (2014). Continuing psychometric evaluation of the Perinatal Grief Intensity Scale in the subsequent pregnancy after perinatal loss. J. Obstet. Gynecol. Neonatal. Nurs. 43:S82. doi: 10.1111/ 1552-6909.12439

Hutti, M. H., and Baker, L. A. (2020). "Assessing perinatal grief intensity in the palliative care setting," in Handbook of Perinatal and Neonatal Palliative Care, eds R. Limbo, C. Wool, and B. S. Carter (Berlin: Springer), 371-383.

Hutti, M. H., DePacheco, M., and Smith, M. (1998). A study of miscarriage: development and validation of the perinatal grief intensity scale. J. Obstet. Gynecol. Neonatal. Nurs. 27, 547-555. doi: 10.1111/j.1552-6909.1998.tb02621.x

Hutti, M. H., Myers, J., Hall, L. A., Polivka, B. J., White, S., Hill, J., et al. (2017). Predicting grief intensity after recent perinatal loss. J. Psychosom. Res. 101, 128-134. doi: 10.1016/j.jpsychores.2017.07.016

Hutti, M. H., Myers, J. A., Hall, L. A., Polivka, B. J., White, S., Hill, J., et al. (2018). Predicting need for follow-up due to severe anxiety and depression symptoms after perinatal loss. J. Obstet. Gynecol. Neonatal. Nurs. 47, 125-136. doi: $10.1016 /$ j.jogn.2018.01.003

Johnson, J. W. (2000). A heuristic method for estimating the relative weight of predictor variables in multiple regression. Multiv. Behav. Res. 35, 1-19. doi: 10.1207/S15327906MBR3501_1

Johnson, J. W., and LeBreton, J. M. (2004). History and use of relative importance indices in organizational research. Organ. Res. Methods 7, 238-257. doi: 10. $1177 / 1094428104266510$

Johnson, M. P., and Baker, S. R. (2004). Implications of coping repertoire as predictors of men's stress, anxiety and depression following pregnancy, childbirth and miscarriage: a longitudinal study. J. Psychosom. Obstetr. Gynecol. 25, 87-98. doi: 10.1080/01674820412331282240
Jones, K., Robb, M., Murphy, S., and Davies, A. (2019). New understandings of fathers' experiences of grief and loss following stillbirth and neonatal death: a scoping review. Midwifery 79:102531. doi: 10.1016/j.midw.2019.10 2531

Kersting, A., and Wagner, B. (2012). Complicated grief after perinatal loss. Dialog. Clin. Neurosci. 14, 187-194. doi: 10.31887/DCNS.2012.14.2/akersting

Lang, A., Fleiszer, A. R., Duhamel, F., Sword, W., Gilbert, K. R., and CorsiniMunt, S. (2011). Perinatal loss and parental grief: the challenge of ambiguity and disenfranchised grief. OMEGA J. Death Dying 63, 183-196. doi: 10.2190/ OM.63.2.e

Lasker, J. N., and Toedter, L. J. (1991). Acute versus chronic grief: the case of pregnancy loss. Am. J. Orthopsychiatry 61, 510-522. doi: 10.1037/h007 9288

McClowry, S. G., Davies, E. B., May, K. A., Kulenkamp, E. J., and Martinson, I. M. (1987). The empty space phenomenon: the process of grief in the bereaved family. Death Stud. 11, 361-374. doi: 10.1080/07481188708252200

McCreight, B. S. (2004). A grief ignored: narratives of pregnancy loss from a male perspective. Sociol. Health Illness 26, 326-350. doi: 10.1111/j.1467-9566.2004. 00393.x

Mulvihill, A., and Walsh, T. (2014). Pregnancy loss in rural Ireland: an experience of disenfranchised grief. Br. J. Soc. Work 44, 2290-2360. doi: 10.1093/bjsw/ bct078

Murphy, K. R., and Myors, B. (2004). Statistical Power Analysis, 2nd Edn. Mahwah, NJ: Lawrence Erlbaum Associates.

Murphy, S., Shevlin, M., and Elklit, A. (2014). Psychological consequences of pregnancy loss and infant death in a sample of bereaved parents. J. Loss Trauma 19, 56-69. doi: 10.1080/15325024.2012.735531

National Institute of Mental Health (2019). Post-Traumatic Stress Disorder. Bethesda, MD: National Institute of Mental Health

Nietlisbach, G., and Maercker, A. (2009). Effects of social exclusion in trauma survivors with posttraumatic stress disorder. Psychol. Trauma Theory Res. Pract. Policy 1, 323-331. doi: 10.1037/a0017832

Panuthos, C., and Romeo, C. (1984). Ended Beginnings: Healing Childbearing Losses. New York, NY: Warner Books.

Potvin, L., Lasker, J., and Toedter, L. (1989). Measuring grief: a short version of the Perinatal Grief Scale. J. Psychopathol. Behav. Assess. 11, 29-45. doi: 10.1007/ BF00962697

Prigerson, H. G., Boelen, P. A., Xu, J., Smith, K. V., and Maciejewski, P. K. (2021). Validation of the new DSM-5-TR criteria for prolonged grief disorder and the PG-13-Revised (PG-13-R) scale. World Psychiatry 20, 96-106. doi: 10.1002/wps. 20823

Renner, C. H., Verdekal, S., Brier, S., and Fallucca, G. (2000). The meaning of miscarriage to others: is it an unrecognized loss? J. Pers. Interpers. Loss 5, 65-76. doi: 10.1080/10811440008407847

Setubal, M. S., Bolibio, R., Jesus, R. C., Benute, G. G., Bibelli, M. A., Bertolassi, N., et al. (2021). A systematic review of instruments measuring grief after perinatal loss and factors associated with grief reactions. Palliat. Support. Care 19, 246-256. doi: 10.1017/S1478951520000826

Stroebe, M., Finkenauer, C., Wijngaards-de Meij, L., Schut, H., van den Bout, J., and Stroebe, W. (2013). Partner-oriented self-regulation among bereaved parents: the costs of holding in grief for the partner's sake. Psychol. Sci. 24, 395-402. doi: $10.1177 / 0956797612457383$

Swanson, K. M., Chen, H. T., Graham, J. C., Wojnar, D. M., and Petras, A. (2009). Resolution of depression and grief during the first year after miscarriage: a randomized controlled clinical trial of couples-focused interventions. J. Women Health 18, 1245-1257. doi: 10.1089/jwh.2008.1202

Toedter, L. J., Lasker, J. N., and Alhadeff, J. M. (1988). The perinatal grief scale: development and initial validation. Am. J. Orthopsychiatry 58, 435-449. doi: 10.1111/j.1939-0025.1988.tb01604.x

Tonidandel, S., and LeBreton, J. M. (2011). Relative importance analysis: a useful supplement to regression analysis. J. Bus. Psychol. 26, 1-9. doi: 10.1007/s10869010-9204-3

Tonidandel, S., and LeBreton, J. M. (2015). RWA Web: a free, comprehensive, web-based, and user-friendly tool for relative weight analysis. J. Bus. Psychol. 30, 207-216. doi: 10.1007/s10869-014-9351-z

Van Der Kolk, B. (2015). The Body Keeps the Score: Brain, mind, and Body in the Healing of Trauma. New York, NY: Penguin Publishing Group.

Weathers, F. W., Litz, B. T., Keane, T. M., Palmieri, P. A., Marx, B. P., and Schnurr, P. P. (2013). The PTSD Checklist for DSM-5 (PCL-5) - Standard 
[Measurement Instrument]. Available online at: https:/www.ptsd.va.gov/ professional/assessment/adult-sr/ptsd-checklist.asp (accessed July 1, 2021).

Wesselmann, E. D., DeSouza, E. R., AuBuchon, S., Bebel, C., and Parris, L. (2021). Investigating microaggressions against transgender individuals as a form of social exclusion. Psychol. Sex. Orient. Gender Divers. doi: 10.1037/sgd0000513 [Epub ahead of print].

Wesselmann, E. D., Ispas, D., Olson, M. D., Swerdlik, M. E., and Caudle, N. M. (2018). Does perceived ostracism contribute to mental health concerns among veterans who have been deployed? PLoS One 13:e0208438. doi: 10.1371/journal. pone. 0208438

Williams, K. D. (2009). "Ostracism: effects of being excluded and ignored," in Advances in Experimental Social Psychology, Vol. 41, ed. M. P. Zanna (Cambridge, MA: Academic Press), 275-314.

Wolf, W., Levordashka, A., Ruff, J. R., Kraaijeveld, S., Lueckmann, J. M., and Williams, K. D. (2015). Ostracism online: a social media ostracism paradigm. Behav. Res. Methods 47, 361-373. doi: 10.3758/s13428-014-0475-x
Conflict of Interest: The authors declare that the research was conducted in the absence of any commercial or financial relationships that could be construed as a potential conflict of interest.

Publisher's Note: All claims expressed in this article are solely those of the authors and do not necessarily represent those of their affiliated organizations, or those of the publisher, the editors and the reviewers. Any product that may be evaluated in this article, or claim that may be made by its manufacturer, is not guaranteed or endorsed by the publisher.

Copyright $\odot 2022$ Wesselmann and Parris. This is an open-access article distributed under the terms of the Creative Commons Attribution License (CC BY). The use, distribution or reproduction in other forums is permitted, provided the original author(s) and the copyright owner(s) are credited and that the original publication in this journal is cited, in accordance with accepted academic practice. No use, distribution or reproduction is permitted which does not comply with these terms. 